\title{
Epidemiological Characterization of Brain Tumors in Colombia, a 10-
} Year Period

\author{
Juan Carlos Gómez-Vega ${ }^{1 *}$, Maria Isabel Ocampo Navia² ${ }^{2}$ Esther de Vries ${ }^{3}$ and Oscar Feo Lee ${ }^{4}$
}

15-PGY of neurosurgery, Pontifica Universidad Javeriana, Faculty of Medicine, San Ignacio University Hospital, Bogotá, Colombia. ${ }^{2}$ Medical Degree, Pontificia Universidad Javeriana-Hospital Universitario San Ignacio, Bogotá, Colombia.

${ }^{3} \mathrm{PhD}$, MSc, Associate Professor of Epidemiology, Department of Clinical Epidemiology and Biostatistics, Pontificia Universidad Javeriana, Bogotá, Colombia.

${ }^{4}$ Neurosurgeon, San Ignacio University Hospital, Faculty of Medicine, Pontifica Universidad Javeriana, Bogotá, Colombia. Master's student in clinical epidemiology, Pontificia Universidad Javeriana.

*Corresponding Author: Juan Carlos Gómez-Vega, 5-PGY of neurosurgery, Pontifica Universidad Javeriana, Faculty of Medicine, San Ignacio University Hospital Bogotá, Colombia

Received date: March 29, 2021; Accepted date: April 12, 2021; Published date: April 16, 2021

Citation: Juan Carlos Gómez-Vega., Maria Isabel Ocampo Navia., Esther de Vries., and Oscar Feo Lee.,(2021) Epidemiological Characterization of Brain Tumors in Colombia, a 10-Year Period. J. Neuroscience and Neurological Surgery. 9(1); DOI:10.31579/2578-8868/173

Copyright: (C) 2021 Juan Carlos Gómez-Vega, This is an open-access article distributed under the terms of The Creative Commons Attribution License, which permits unrestricted use, distribution, and reproduction in any medium, provided the original author and source are credited

\begin{abstract}
:
Introduction: Central nervous system tumors are rare; in 2015 they represented approximately $1.4 \%$ of new cancer diagnoses, causing $2.6 \%$ of deaths by cancer that year. In Colombia, there are few reports on the epidemiology of brain tumors, and those that exist are local databases that do not have a rigorous and massive registry. Due to limited epidemiological information in our country, this document aims to characterize the epidemiology of brain tumors in Colombia over a 10 -year period.

Methods: A retrospective descriptive observational study was conducted, using databases of population-based cancer registries in Colombia. We extracted information from a 10-year period recorded in patients with tumors without age group restriction. A descriptive analysis was carried out for all the variables considered, the incidence and mortality rates per 100,000 person years were calculated. Statistical software Stata 14.0 was used.

Results: Our analysis was performed with a population of 775 adult patients and 123 pediatric patients, with an incidence of 1.55 per 100.000 individuals in the pediatric population and 3.19 per 100.000 individuals in the adult population. The mortality rate for pediatric and adult patients was 0.063 per 100.000 individuals and 1.86 per 100.000 individuals respectively. The most frequent tumors in the pediatric age group were neuroepithelial tumors, embryonal tumors and ependymal tumors, whereas for adults, the most frequent were neuroepithelial tumors, meningiomas and hematolymphoid tumors.

Conclusions: This study constitutes the most recent work on the epidemiology of brain tumors in Colombia. There was a clear general underreporting and statistics lower than those compared with the literature. It is intended to expand coverage and data collection in population-based cancer registries.

Key words: transnasal- trans; sphenoidal; elderly; hypopituitarism
\end{abstract}

\section{Introduction}

Nervous system tumors are rare, and accounted for approximately $1.4 \%$ of the new cancer diagnoses in 2015 in the United States. These tumors caused $2.6 \%$ of cancer deaths in that year; they have a greater clinical involvement in children and young adults, and cause approximately $30 \%$ and $20 \%$ of cancer deaths, respectively [1-6]. Their prevalence decreases with age; these tumors are the first cause of neoplasm in the 0-14 year age group, and the third cause in the 15-39 year age group, preceded by breast and thyroid cancer, and are within the less common neoplasms in patients older than 40 years $[1,7,8]$. The most common central nervous system (CNS) tumors in pediatric age are pilocytic astrocytoma, embryonal tumors and malignant gliomas, while meningiomas, pituitary tumors and malignant gliomas are found in adults [1-3,9-13].

CNS tumors represent a diagnostic and therapeutic challenge, because the differentiation between malignant and benign may be unclear. In addition, a complete surgical resection is not always achieved, which results in relapses, in an important compromise of the neurological function, and can be potentially fatal [14-18]. It is necessary to know their incidence, mortality and epidemiology, to implement health policies and diagnostic screening $[19,20]$. 
There are few reports on the disease burden of brain tumors in Colombia. This information is necessary in order to implement health policies, develop strategies to plan preventive activities, build capacities in the provision of health services, improve the quality of medical care and plan clinical trials [21,22]. This work aims to provide epidemiological information on brain tumors from a 10-year period, collected from population-based cancer registries in different cities of our country. This in order to generate knowledge and provide data to the actors involved in the social security system and to the health regulatory agencies, in order to create promotion actions, and to ensure prevention and early detection of brain tumors.

\section{Materials and Methods}

A descriptive observational retrospective study was conducted, using databases of Colombian population-based cancer registries (RCBPs, by their Spanish acronym). Data were collected at the Cancer Information System in Colombia (SICC-infocancer, by its Spanish acronym) center, which collects general information on mortality and incidence from the cities of Bucaramanga, Pasto, Manizales and Barranquilla [23,24]. Attached is the individual population registry of Cali, Valle del Cauca, Colombia [25] and of international agencies (network of national cancer institutes, Ministry of Health, IARC/GLOBOCAN) [3,4]. Anonymised data from patients with brain tumors (malignant or benign) were obtained for the 2003-2012 period; this information was grouped without agegroup restriction into 2 groups: pediatric (under 18 years old) and adults (older than or equal to 19 years old). The general population characteristics and the characterization of brain tumors were analyzed. The general mortality for each department of Colombia presented in SICC-Infocancer was calculated, but it was extracted from the DANE (National Administrative Department of Statistics). Averages of standardized mortality rates were obtained, grouped by 5 years (20032007 and 2008-2012); this was done for greater comfort when performing the analyzes, without affecting the reliability of the data due to the minimum variability during the 10 -year period. On the other hand, since the registry covers the 2003-2012 period, the classification prior to the latest update proposed by the WHO in 2016 was used for the histological reference of the tumor subtypes.

\section{Statistical analysis}

For the statistical analysis, a database with the collected data and raw information was created, and a descriptive statistical analysis was performed for all the variables considered in the analysis and for the selected subgroups. The Shapiro-Wilk test was applied to determine the normality of the data; data that followed a normal distribution are presented as average and standard deviation; categorical variables are presented in proportions or percentages. Incidence and mortalities are presented as relative frequencies, crude rates and age-adjusted rates (under 18 and over 18) expressed per 100,000 person-years; the standard population used was the world population according to SEGI, as is conventional to compare standardized rates using population-based cancer registry data [23]. The Stata 14.0 statistical program was used for the statistical analysis.

\section{Results}

Pediatric Central Nervous System Tumors

\section{General demographic characteristics}

During the 2003-2012 period, a total of 123 cases of brain tumors were reported in SICC-infocancer in the pediatric population. $53.7 \%$ of these cases corresponded to men, with an average age at the time of diagnosis of 8.4 years (SD: +- 5.43 years). Regarding their behavior, $95.1 \%$ were malignant, $3.3 \%$ of uncertain behavior and $1.6 \%$ were benign (Table 1).

\section{Characterization of brain tumors}

Malignant supratentorial tumors were the most common, which represented $63.4 \%$ (Supplement 1). According to the histological subgroup, the most common in ascending order were glial lesions, embryonal tumors and ependymal tumors, of which the predominant histological subtypes were astrocytoma, medulloblastoma and ependymoma (Supplement 2). Regarding their location, parenchymal tumors were the most common at supratentorial level, and of these, temporal and parietal lobe lesions were the most significant, followed by overlapping and ventricular lesions. On the other hand, cerebellar lesions were the most common site of infratentorial lesion localization (Supplement 3).

\begin{tabular}{|c|l|c|c|}
\hline ICD-10 & CODE & $\mathbf{n}$ & \% \\
\hline \multicolumn{1}{|c|}{ SUPRATENTORIAL TUMORS } & $\mathbf{5 1}$ & $\mathbf{4 1 . 4 6}$ \\
\hline \multicolumn{1}{|c|}{ Malignant supratentorial neoplasms } & 48 & 39.02 \\
\hline C719 & Malignant neoplasm of brain, unspecified site & 29 & 23.58 \\
\hline C712 & Malignant neoplasm of temporal lobe & 4 & 3.25 \\
\hline C713 & Malignant neoplasm of parietal lobe & 4 & 3.25 \\
\hline C711 & Malignant neoplasm of frontal lobe & 3 & 2.44 \\
\hline C715 & Malignant neoplasm of cerebral ventricle & 2 & 1.63 \\
\hline C729 & $\begin{array}{l}\text { Malignant neoplasm of central nervous system, without other } \\
\text { specification }\end{array}$ & 2 & 1.63 \\
\hline C723 & Malignant neoplasm of optic nerve & 1 & 0.81 \\
\hline C714 & Malignant neoplasm of occipital lobe & 1 & 0.81 \\
\hline D430 & $\begin{array}{l}\text { Neoplasm of uncertain or unknown behavior of brain, } \\
\text { supratentorial }\end{array}$ & 1 & 0.81 \\
\hline D332 & Benign neoplasm of brain, unspecified site & 1 & 0.81 \\
\hline C719 & Malignant neoplasm of brain, unspecified site & 29 & 23.58 \\
\hline
\end{tabular}




\begin{tabular}{|c|l|c|c|}
\hline \multicolumn{2}{|c|}{ Extra-CNS malignant tumors } & 3 & 2.43 \\
\hline C720 & Malignant neoplasm of spinal cord & 2 & 1.63 \\
\hline C700 & Malignant neoplasm of cerebral meninges & 1 & 0.81 \\
\hline \multicolumn{2}{|l|}{ MALIGNANT INFRATENTORIAL TUMORS } & $\mathbf{3 9}$ & $\mathbf{3 1 . 7 0}$ \\
\hline C716 & Malignant neoplasm of cerebellum & 24 & 19.51 \\
\hline C717 & Malignant neoplasm of cerebral peduncle & 14 & 11.38 \\
\hline D431 & Neoplasm of uncertain or unknown behavior of brain, infratentorial & 1 & 0.81 \\
\hline & & $\mathbf{3 3}$ & $\mathbf{2 6 . 8 2}$ \\
\hline C830 & Small-cell non-follic lymphoma & 1 & 0.81 \\
\hline D432 & $\begin{array}{l}\text { Neoplasm of uncertain or unknown behavior of brain, unspecified } \\
\text { site }\end{array}$ & 2 & 1.63 \\
\hline C718 & Lesion of contiguous sites of brain & 5 & 4.07 \\
\hline C710 & Malignant neoplasm of brain, except lobes and ventricles & 25 & 20.33 \\
\hline \multicolumn{2}{|c|}{ TOTAL } & 123 & 100.0 \\
\hline
\end{tabular}

Supplement 1: characterization of tumors of the pediatric population by icd-10 code

\begin{tabular}{|c|c|c|c|}
\hline ICD-O3 & CODE & $\mathbf{n}$ & $\%$ \\
\hline 8000 & Neoplasm & 30 & 24.39 \\
\hline \multicolumn{2}{|c|}{ ASTROCYTIC AND OLIGODENDROGLIAL TUMORS } & 68 & 30.89 \\
\hline \multicolumn{2}{|r|}{ Astrocytomas } & 29 & 23.58 \\
\hline 9400 & Astrocytoma & 17 & 13.82 \\
\hline 9401 & Anaplastic astrocytoma & 5 & 4.07 \\
\hline 9420 & Fibrillar astrocytoma & 3 & 2.44 \\
\hline 9421 & Pilocytic astrocytoma & 2 & 1.63 \\
\hline 9424 & Pleomorphic xantoastrocytoma & 1 & 0.81 \\
\hline 9430 & Astroblastoma & 1 & 0.81 \\
\hline \multicolumn{2}{|r|}{ Glial tumors } & 9 & 7.32 \\
\hline 9440 & Glioblastoma & 7 & 5.69 \\
\hline 9380 & Malignant glioma & 2 & 1.63 \\
\hline \multicolumn{2}{|r|}{ EMBRYONAL TUMORS } & 32 & 26.02 \\
\hline 9470 & Medulloblastoma & 20 & 16.26 \\
\hline 9473 & Primitive neuroectodermal tumor & 7 & 5.69 \\
\hline 9471 & Desmoplastic nodular medulloblastoma & 2 & 1.63 \\
\hline 9500 & Neuroblastoma & 2 & 1.63 \\
\hline 9474 & Medulloblastoma & 1 & 0.81 \\
\hline \multicolumn{2}{|r|}{ EPENDYMAL TUMORS } & 14 & 11.38 \\
\hline 9391 & Ependymoma & 8 & 6.50 \\
\hline 9392 & Anaplastic ependymoma & 6 & 4.88 \\
\hline \multicolumn{2}{|r|}{ GERM CELL TUMORS } & 3 & 2.44 \\
\hline 9080 & Teratoma & 2 & 1.63 \\
\hline 9064 & Germinoma & 1 & 0.81 \\
\hline \multicolumn{2}{|r|}{ OTHER TYPES OF TUMORS } & 6 & 4.88 \\
\hline 9390 & $\begin{array}{l}\text { Atypical choroid plexus papilloma/choroid plexus } \\
\text { carcinoma }\end{array}$ & 1 & 0.81 \\
\hline
\end{tabular}




\begin{tabular}{|c|l|c|c|}
9530 & Meningioma & 1 & 0.81 \\
\hline 9560 & Neurilemoma & 1 & 0.81 \\
\hline 9670 & Malignant lymphoma of small B lymphocytes & 1 & 0.81 \\
\hline 8002 & Malignant tumor, small cell type & 1 & 0.81 \\
\hline 8800 & Sarcoma & 1 & 0.81 \\
\hline TOTAL & & 123 & 100.00 \\
\hline
\end{tabular}

Supplement 2: Characterization of tumors of the pediatric population by histology

\begin{tabular}{|c|c|c|c|}
\hline Code & Site & $\mathbf{n}$ & $\%$ \\
\hline \multicolumn{2}{|r|}{ SUPRATENTORIAL } & 81 & 65.85 \\
\hline \multicolumn{2}{|r|}{ Brain parenchyma } & 79 & 64.23 \\
\hline 719 & Brain, without other specification & 31 & 25.20 \\
\hline 710 & Brain & 26 & 21.14 \\
\hline 718 & Overlapping lesion of brain & 5 & 4.07 \\
\hline 712 & Temporal lobe & 4 & 3.25 \\
\hline 713 & Parietal lobe & 4 & 3.25 \\
\hline 715 & Ventricles & 4 & 3.25 \\
\hline 711 & Frontal lobe & 3 & 2.44 \\
\hline 714 & Occipital lobe & 1 & 0.81 \\
\hline 723 & Optic nerve & 1 & 0.81 \\
\hline 719 & Brain, without other specification & 31 & 25.20 \\
\hline \multicolumn{2}{|r|}{ Other } & 2 & 1.63 \\
\hline 729 & Nervous system, without other specification & 2 & 1.63 \\
\hline \multicolumn{2}{|r|}{ INFRATENTORIAL } & 39 & 31.71 \\
\hline 716 & Cerebellum & 25 & 20.33 \\
\hline 717 & Brain stem & 14 & 11.38 \\
\hline \multicolumn{2}{|r|}{ OTHER LOCATIONS } & 3 & 2.44 \\
\hline 720 & Spinal cord & 2 & 1.63 \\
\hline 700 & Brain meninges & 1 & 0.81 \\
\hline TOTAL & & 123 & 100.0 \\
\hline
\end{tabular}

Supplement 3: Characterization of tumors of the pediatric population by location

\section{$\underline{\text { Incidence and mortality }}$}

Incidence was similar between males and females in the different cities, being lower for the female population (Table 2). Regarding mortality, the crude and standardized rate was 0.12 and 0.06 per 100,000 population, respectively.

\section{ADULT CENTRAL NERVOUS SYSTEM TUMORS}

\section{General characteristics}

A total of 775 cases of brain tumors in adults were reported to SICCinfocancer. The average age of presentation was 52.7 years (SD: +-17.1 years), with an equitable distribution between genders. Overall, $92.1 \%$ of the tumors had a malignant behavior, $7 \%$ had a benign behavior, and $0.9 \%$ an uncertain behavior. The main basis of the diagnosis was histological, and represented $73.8 \%$ of the cases (Table 1). 


\begin{tabular}{|c|c|c|c|c|}
\hline \multirow[b]{2}{*}{ Variable } & \multicolumn{2}{|c|}{ Pediatric } & \multicolumn{2}{|c|}{ Adults } \\
\hline & $\mathrm{n}=\mathbf{1 2 3}$ & $\%$ & $n=775$ & $\%$ \\
\hline Age & \multicolumn{2}{|c|}{$8.39+-5.43$} & \multicolumn{2}{|c|}{$52.7+-17.1$} \\
\hline \multicolumn{5}{|l|}{ Tumor sequence } \\
\hline Single tumor & 123 & $100 \%$ & 760 & 98.06 \\
\hline First of more & 0 & $0 \%$ & 7 & 0.90 \\
\hline Second of more & 0 & $0 \%$ & 8 & 1.03 \\
\hline \multicolumn{5}{|l|}{ Gender } \\
\hline Male & 66 & 53.66 & 386 & 49.81 \\
\hline Female & 57 & 46.34 & 389 & 50.19 \\
\hline \multicolumn{5}{|l|}{ Behavior } \\
\hline Malignant, primary location & 117 & 95.12 & 714 & 92.1 \\
\hline Uncertain if it is benign or malignant & 4 & 3.25 & 7 & 0.9 \\
\hline Benign & 2 & 1.63 & 54 & 6.97 \\
\hline \multicolumn{5}{|l|}{ Diagnostic basis } \\
\hline DCO* & 7 & 5.69 & 88 & 11.35 \\
\hline Clinical & 25 & 20.33 & 115 & 14.84 \\
\hline Microscopic verification & 91 & 73.98 & 572 & 73.81 \\
\hline \multicolumn{5}{|l|}{ Vital status } \\
\hline Alive & 36 & 29.27 & 192 & 24.77 \\
\hline Dead & 61 & 49.59 & 453 & 58.45 \\
\hline No data & 26 & 21.14 & 130 & 16.77 \\
\hline
\end{tabular}

DCO* Death Certificate Only

Table 1: Sociodemographic characterization of the pediatric and adult population

\section{Characterization of brain tumors}

Overall, $92 \%$ of the tumors were supratentorial, $4 \%$ were infratentorial and $2 \%$ were hematolymphoid (Supplement 4). Glial lesions, meningiomas and hematolymphoid tumors were the most common histological types, with $82.4 \%, 8.9 \%$ and $2.3 \%$, respectively (Supplement 5). Regarding supratentorial lesions, the temporal lobe was the most commonly compromised site (7.6\%); and for infratentorial lesions, the cerebellum was the most common site, with $22 \%$ of cases (Supplement $6)$.

\section{Incidence and mortality}

The incidence behaved similarly in different cities for both sexes (Table 2). Regarding mortality, the crude and standardized rate was 2.8 and 1.9 per 100,000 population, respectively.

\begin{tabular}{|c|c|c|c|c|c|c|}
\hline & \multicolumn{3}{|c|}{ Pediatric } & \multicolumn{3}{|c|}{ Adults } \\
\hline & Frequency $(\mathrm{N})$ & Raw rate & Standardized Rate & Frequency $(\mathrm{N})$ & Raw rate & Standardized Rate \\
\hline & \multicolumn{6}{|c|}{ INCIDENCE } \\
\hline Region & \multicolumn{6}{|c|}{ Men } \\
\hline Bucaramanga & 59 & 3.07 & 1.24 & 259 & 8.29 & 5.47 \\
\hline Pasto & 13 & 1.78 & 0.84 & 67 & 5.68 & 3.68 \\
\hline Manizales & 10 & 1.4 & 0.61 & 56 & 4.72 & 2.89 \\
\hline Barranquilla & 21 & 1.41 & 0.57 & 106 & 4.53 & 3.01 \\
\hline \multirow[t]{2}{*}{ Cali } & SD & 5.1 & 5.35 & SD & 5 & 5.1 \\
\hline & \multicolumn{6}{|c|}{ Women } \\
\hline Bucaramanga & 43 & 2.3 & 0.91 & 241 & 6.64 & 4.1 \\
\hline Pasto & 14 & 1.86 & 0.8 & 70 & 5.05 & 3.13 \\
\hline Manizales & 9 & 1.29 & 0.55 & 34 & 2.44 & 1.48 \\
\hline Barranquilla & 11 & 0.74 & 0.3 & 106 & 4.07 & 2.2 \\
\hline \multirow[t]{2}{*}{ Cali } & SD & 4.6 & 4.4 & $\mathrm{SD}$ & 4.6 & 4.3 \\
\hline & \multicolumn{6}{|c|}{ Both } \\
\hline Bucaramanga & 100 & 2.68 & 1.07 & 499 & 7.4 & 4.7 \\
\hline Pasto & 27 & 1.76 & 0.83 & 137 & 5.34 & 3.39 \\
\hline Manizales & 18 & 1.36 & 0.57 & 90 & 3.48 & 2.12 \\
\hline Barranquilla & 31 & 1.086 & 0.43 & 220 & 4.07 & 2.59 \\
\hline Cali & SD & 4.85 & 4.88 & SD & 4.8 & 4.7 \\
\hline
\end{tabular}




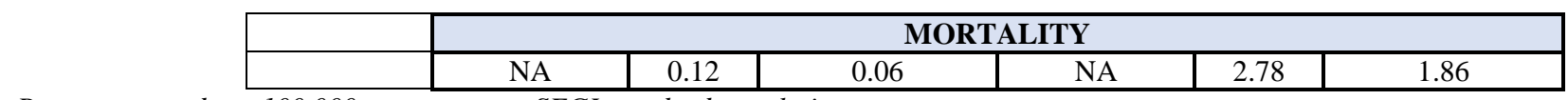

Rates expressed per 100,000 person-years, SEGI standard population

Table 2: Incidence and mortality in the pediatric and adult population

\section{DISCUSSION}

Data from 775 adult patients and 123 pediatric patients were obtained. Incidence and mortality in adults were 3.2 per 100,000 population and 1.9 per 100,000 population, respectively. Incidence and mortality in the pediatric population were 1.6 per 100,000 population and 0.06 per 100,000 population, respectively. In 2012 , the worldwide age-adjusted incidence rate of primary malignant brain tumors and other CNS tumors using the global population standard was 3.4 per 100,000 population. Incidence rates were higher in more developed countries (5.1 per 100,000 population) than in less developed countries ( 3.0 per 100,000 population). In the United States, brain and other CNS tumors were the most common cancer site in people aged between 0-14 years, with an annual average age-adjusted incidence rate of 5.54 per 100,000 population; people over 40 years of age had an annual average age-adjusted incidence of 40.82 per 100,000 population [26].

When comparing these international data, the incidence rates observed in Colombia are low compared to those in high-income countries, where the rates range between 10.57 and 25.5, in countries such as Japan, France and Italy [31-34]. However, the rates are similar to those of Latin American countries, such as Brazil, Mexico and Ecuador where the incidence rates were 5.5, 2.4 and 3.7 per 100,000 population, respectively [8]. Mortality figures are similar: the average annual mortality rate in the US between 2010 and 2014 was 4.3 per 100,000 population, and it is estimated that 16,616 deaths will be attributed to primary malignant brain and other CNS tumors in the United States in 2018 (26). Similarly, Australia reported a crude death rate of 5.3 per 100,000 population [35]. On the contrary, a crude death rate of 3.6, 1.9 and 1.9 per 100,000 population was reported in Brazil, Mexico and Ecuador, respectively [8]. Standardized rates are similar between different cities, which gives even more credibility to their levels. The slightly lower level reported in Manizales, a relatively small city, may be due to diagnoses made outside the city, difficulty in registering all CNS tumors and, perhaps, to an underdiagnosis.

Pediatric and adult populations differ in terms of tumor characteristics. According to the literature, embryonal tumors and low-grade and highgrade glial lesions constitute the most common tumors in the pediatric population; it is worth mentioning that the frequency varies according to age subgroups [26]. This is consistent with our study, in which embryonal tumors (26\%), astrocytomas (23.5\%) and ependymomas (11.4), constituted the main histological subtypes within CNS tumors in this population. On the contrary, the retrospective study by Paez et al showed that in the pediatric population the most common primary CNS tumor was medulloblastoma [27]. Chater-Cure et al had similar findings, since in the

11 pediatric patients 3 medulloblastomas and 3 gliomas were found [28]. These two findings clearly demonstrate the great difference between data from case series and hospitals in particular, versus population-based data. The most common tumor location in the pediatric population was the supratentorial, temporoparietal lobe, which coincides with the literature [26].

The location of tumors in adults was similar to that of the pediatric population; the supratentorial location was even more predominant, with $92 \%$. As for tumor histology, the fact that $30 \%$ of cases do not have histology details complicates their interpretation. In cases with information on the histological subtype, the three main tumors in descending order were glial lesions (high-grade), meningiomas, and hematolymphoid tumors, but with much lower proportions than those reported in the literature. The fact that hematolymphoid tumors are among the 3 most common tumors differs from the literature, which reports sellar lesions (pituitary adenomas) within the 3 most common types of tumors. Usually, they are reported as follows: meningiomas (36.8\%), followed by pituitary tumors $(16.2 \%)$ and glioblastomas (14.9\%). In the study by Paez et al, the most common primary tumors were gliomas, and of these the highest proportion was glioblastoma $(17.9 \%)$, followed by meningioma (10.3\%) [27]. Similarly, Bray et al reported in a population-based database that $62.1 \%$ of the nervous system tumors corresponded to neuroepithelial tumors, and within these, approximately $89 \%$ corresponded to gliomas, $10 \%$ to embryonal tumors, and less than $1 \%$ were classified as "Others" [5]. In the US registry of brain tumors, meningiomas were the most common, accounting for about $36.8 \%$ of tumors in general; of these, $79 \%$ were located in the brain meninges and $4.2 \%$ in the spinal meninges. On the other hand, glioblastoma was the third most commonly reported histological subtype; in general, it is the most common malignant tumor, and constitutes $14.9 \%$ of all primary brain tumors and $47.1 \%$ of malignant primary brain tumors [26]

It is remarkable that in this study, pituitary adenomas were not among the most common tumors, something that differs from what is reported in the literature, since pituitary tumors constitute the second most common primary nervous system tumor of in the adult population (16.2\%), with an incidence of 3.98 per 100,000 people according to CBTRUS [26]. This is explained by the high percentage of tumors that are not classified by subtype, and perhaps by a underreporting in the databases or a subdiagnosis by the presence of patients with asymptomatic or intervened lesions.

\section{Limitations and future directions}

In Colombia, there are very few reports on the epidemiology of brain tumors $[19,27,36]$ and those that exist are from hospital records or specialized centers, which do not have a rigorous and massive registry or represent the entire population of patients, unlike European or US databases. In 5 of the 118 cities in our country there is a formal population-based cancer registry. In addition, these databases have general data that lack relevant details, such as specific characteristics in the follow-up and characterization in the histopathological diagnosis, among others. Another important limitation in our country is the difficult access to an integrated and uniform network system for registration in databases in the different cities [29,30,37]. Although the present study does not reflect the epidemiology of brain tumors throughout Colombia, given that the results obtained only represent some cities, we consider that the study gathers the most up-to-date and population-based data on brain tumors in Colombia. Since the incidence of CNS tumors does not normally show strong changes in its incidence or mortality, these data from the 2002-2012 period help us create tactics to improve decision making in this group of patients, and to implement public health strategies that allow planning preventive activities and clinical trials to improve the quality of medical care [20,38]. In addition, the results help us to visualize the current situation of the Colombian databases, in which histological and location data and other details are missing, such as the clinical stage 
at the time of diagnosis. It would be important to work on achieving a sound and detailed registry that gathers the most important variables on brain tumors, to know the real epidemiology, which allows finding health system flaws to implement the necessary solutions.

\section{CONCLUSIONS}

The present study is the most recent work on the characterization, epidemiology, incidence and mortality of brain tumors in Colombia from a 10-year period, whose statistics are low compared to what is reported in the literature. We consider that for future population studies it is essential to expand coverage and data collection in population-based cancer registries, which are necessary to implement health policies and strategies.

\section{Conflict of interest}

All authors declare that they have no conflict of interest in relation to the publication of this manuscript.

\section{Acknowledgments}

To SICC-infocancer and the population-based cancer registries in Colombia for their great cooperation in sending the anonymized databases. Without their help this article could not have been made.

\section{References}

1. Ostrom QT, Gittleman H, Xu J, Kromer C, Wolinsky Y, Kruchko C, et al. CBTRUS statistical report: Primary brain and other central nervous system tumors diagnosed in the United States in 2009-2013. Neuro Oncol. 2016;18:v1-75.

2. McNeill KA. Epidemiology of Brain Tumors. Neurol Clin. 2016;34(4):981-998.

3. Coebergh JW, Van Den Hurk C, Louwman M, Comber H, Rosso S, Zanetti R, et al. EUROCOURSE recipe for cancer surveillance by visible population-based cancer RegisTrees ${ }^{\circledR}$ in Europe: From roots to fruits. Eur J Cancer. 2015;51(9):10501063.

4. Ferlay J, Soerjomataram I, Dikshit R, Eser S, Mathers C, Rebelo M, et al. Cancer incidence and mortality worldwide: Sources, methods and major patterns in GLOBOCAN 2012. Int J Cancer. 2015;136(5):E359-386.

5. Bray F, Piñeros M. Cancer patterns, trends and projections in latin america and the caribbean: A global context. Salud Publica Mex. 2016;58(2):104-117.

6. Rapalino $\mathrm{O}$, Batchelor $\mathrm{T}$, González RG. Intra-axial brain tumors. Handb Clin Neurol. 2016;135:253-274.

7. Neglia JP, Robison LL, Stovall M, Liu Y, Packer RJ, Hammond $\mathrm{S}$, et al. New primary neoplasms of the central nervous system in survivors of childhood cancer: a report from the Childhood Cancer Survivor Study. J Natl Cancer Inst. 2006 Nov;98(21):1528-1537.

8. Piñeros M, Sierra MS, Izarzugaza MI, Forman D. Descriptive epidemiology of brain and central nervous system cancers in Central and South America. Cancer Epidemiol. 2016;44:S141149.

9. Barnholtz-Sloan JS, Ostrom QT, Cote D. Epidemiology of Brain Tumors. Neurol Clin. 2018 Aug;36(3):395-419.

10. Ntali G, Wass JA. Epidemiology, clinical presentation and diagnosis of non-functioning pituitary adenomas. Pituitary. 2018 Apr;21(2):111-118.

11. Shah V, Kochar P. Brain Cancer: Implication to Disease, Therapeutic Strategies and Tumor Targeted Drug Delivery
Approaches. Recent Pat Anticancer Drug Discov. 2018;13(1):70-85.

12. Fallahi P, Foddis R, Cristaudo A, Antonelli A. High risk of brain tumors in farmers: a mini-review of the literature, and report of the results of a case control study. Clin Ter. 2017; 168(5):e290-292.

13. Strowd RE 3rd, Blakeley JO. Common Histologically Benign Tumors of the Brain. Continuum (Minneap Minn). 2017 Dec;23(6, Neuro-oncology):1680-1708.

14. Gupta T, Epari S, Moiyadi A, Shetty P, Goda JS, Krishnatry R, et al. Demographic profile, clinicopathological spectrum, and treatment outcomes of primary central nervous system tumors: Retrospective audit from an academic neuro-oncology unit. Indian J Cancer. 2017;54(4):594-600.

15. Lapointe S, Perry A, Butowski NA. Primary brain tumours in adults. Lancet (London, England). 2018 Aug;392(10145):432446.

16. Nygaard C, Jensen H, Christensen J, Vedsted P. Health care use before a diagnosis of primary intracranial tumor: a Danish nationwide register study. Clin Epidemiol. 2018;10:809-829.

17. Boutahar FZ, Benmiloud S, El Kababri M, Kili A, El Khorassani M, Allali N, et al. Time to diagnosis of pediatric brain tumors: a report from the Pediatric Hematology and Oncology Center in Rabat, Morocco. Childs Nerv Syst. 2018 Jul;

18. Izycka-Swieszewska E, Bien E, Stefanowicz J, Szurowska E, Szutowicz-Zielinska E, Koczkowska M, et al. Malignant Gliomas as Second Neoplasms in Pediatric Cancer Survivors: Neuropathological Study. Biomed Res Int. 2018;2018:4596812.

19. Pardo, C. Cendales R. Incidencia, mortalidad y prevalencia de Cáncer en Colombia 2007-2011. Vol. 1, Instituto Nacional De Cancerologia. 2015. 148 p.

20. Kissne Horvath I. Patient registries from the view of health policy. Orv Hetil. 2014 May;155(19):729-731.

21. Baldi, I., Engelhardt, J., Bonnet, C., Bauchet, L., Berteaud, E., Grüber, A. and Loiseau H. Epidemiology of meningiomas. Neurochirurgie. 2014;Epub:pii: S0028-3770(14)00112-X.

22. Suárez A, Castellanos M, Simbaqueba A, Gamboa Ó. Aspectos clínicos y demora para el diagnóstico en niños con tumores del sistema nervioso central en el Instituto Nacional de Cancerología de Colombia. Rev Colomb Cancerol. 2011 Jan;15(3):127-134.

23. Yepez MC, Uribe C, Arias N, Navarro E, de Vries E, Gamboa O, Gil OF PC. Sistema de información de cáncer en Colombia - SICC. Instituto Nacional De Cancerologia. 2017.

24. Instituto Nacional de Cancerología Departamento ministrativo de Estadística Nacional. Sistema de información de cáncer en Colombia-SICC. INC, DANE. 2017.

25. Facultad de Salud-Universidad del Valle. Registro Poblacional de Cáncer de Cali. 2005.

26. Ostrom QT, Gittleman H, Liao P, Vecchione-Koval T, Wolinsky Y, Kruchko C, et al. CBTRUS Statistical Report: Primary brain and other central nervous system tumors diagnosed in the United States in 2010-2014. Neuro Oncol. 2017 Nov;19(suppl_5):v1-88.

27. Páez-rodríguez AM, Burbano-erazo NM, Merchancanodelgado CL, Erazo-bravo NJ, Muñoz-bolaños AB. Caracterización de los tumores cerebrales en un Hospital Universitario de Pereira, Colombia : un estudio retrospectivo. Vol. 19. 2013. p. 120-125.

28. Chater-Cure G, Aristizabal G, Aristizabal J, Roa C, Alvarado H. Características demográficas y patológicas de los tumores del sistema nervioso central estudiados en la clínica El Bosque. 
Acta Neurol Colomb [Internet]. 2011;27(1):106-113.

29. Merlano CA, Gorbanev I. Health system in Colombia: a systematic review of literature. Gerenc y Políticas Salud. 2013;12(571):74-86.

30. Calderón CAA, Botero JC, Bolaños JO, Martínez RR. Sistema de salud en Colombia: 20 años de logros y problemas. Cien Saude Colet [Internet]. 2011;16(6):2817-2828.

31. Robles P De, Fiest KM, Frolkis AD, Pringsheim T, Atta C, Germaine- CS, et al. The worldwide incidence and prevalence of primary brain tumors: a systematic review and meta-analysis. Neuro Oncol. 2015;17(October 2014):776-783.

32. Cordera S, Bottacchi E, D'Alessandro G, Machado D, De Gonda F, Corso G. Epidemiology of primary intracranial tumours in NW Italy, a population based study: stable incidence in the last two decades. J Neurol. 2002 Mar;249(3):281-284.

33. Kuratsu J, Takeshima H, Ushio Y. Trends in the incidence of primary intracranial tumors in Kumamoto, Japan. Int $\mathbf{J}$ Clin
Oncol. 2001 Aug;6(4):183-191.

34. Baldi I, Gruber A, Alioum A, Berteaud E, Lebailly P, Huchet A, et al. Descriptive epidemiology of CNS tumors in France : results from the Gironde Registry for the period $2000-2007$. 2011;13(12):1370-1138.

35. Australian Institute of Health and Welfare. Cancer In australia 2017. 2017.

36. Suárez A, Castellanos M, Simbaqueba A, Gamboa Ó. Aspectos clínicos y demora para el diagnóstico en niños con tumores del sistema nervioso central en el Instituto Nacional de Cancerología de Colombia. Rev Colomb Cancerol [Internet]. 2011;15(3):127-134.

37. Planas M, Rodriguez T, Lecha M. La importancia de los datos. Nutr Hosp. 2004;19(1):11-13.

38. Parkin DM. The role of cancer registries in cancer control. Int $\mathrm{J}$ Clin Oncol. 2008;13(2):102-111.
This work is licensed under Creative

Commons Attribution 4.0 License

To Submit Your Article Click Here: Submit Manuscript

DOI: $10.31579 / 2578-8868 / 173$
Ready to submit your research? Choose Auctores and benefit from:

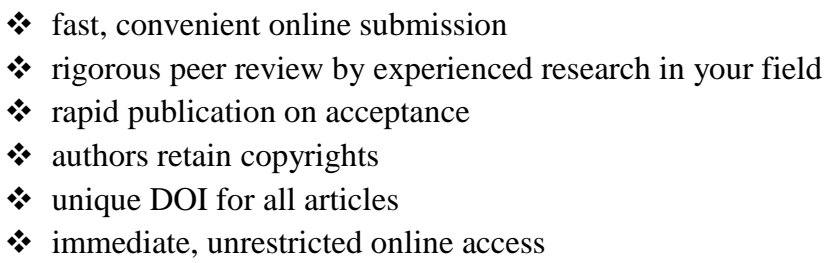

At Auctores, research is always in progress.

Learn more www.auctoresonline.org/journals/neuroscience-andneurological-surgery 